\title{
Machado de Assis e suas múltiplas vozes
}

Jean Pierre Chauvin ${ }^{I}$

$\mathrm{R}$ ESULTADO de quatro anos de pesquisa, e publicado no segundo semestre de 2013, Machado de Assis: critica literária e textos diversos é uma feliz surpresa para os leitores e estudiosos da obra do escritor fluminense - considerado, ainda em vida, como detentor de uma das vozes mais importantes de nossa literatura e imprensa do século XIX.

Trata-se de uma ampla e bem cuidada compilação de artigos de Joaquim Maria Machado de Assis (1839-1908), publicados no período de 1856 (quando ele iniciava sua carreira na Marmota Fluminense) a 1907. Esse dado, por si só, revela o rigor e a abrangência que nortearam o trabalho organizado com rigoroso método pelas autoras - que resgataram numerosas contribuições do escritor em diversos periódicos, incluindo exaustiva pesquisa e seleção dos textos a partir de microfilmes obtidos na Biblioteca Nacional, no Rio de Janeiro.

Com suas mais de 720 páginas, o volume está disposto em duas seções. $\mathrm{Na}$ primeira parte, temos uma breve "Nota explicativa" (p.11 e 12), em que se revela o fato de o material reunido ter sido localizado tanto em livros publicados por editoras tradicionais quanto em periódicos que vieram a público em diferentes épocas de circulação, permitindo "ao leitor acompanhar o desenvolvimento de Machado de Assis, da juventude à maturidade, na prática plural da crítica literária” (p.11).

De fato, à medida que acompanhamos a leitura dos textos lá coligidos, é possível notar uma pluralidade de pontos de vista, orquestrados hábil e lucidamen- te por Machado. Além disso, percebe-se como a própria redação do crítico alterna-se entre momentos de maior acidez ou leniência; maior amplitude ou objetividade, a exemplo do que caracteriza o vai-e-vem dos narradores e personagens que cunhou.

Nas páginas seguintes da coletânea, deparamos com a "Introdução" (p.13 a 49) que logo chama a atenção para a evidente pertinência da publicação em si. Além de ser um excelente material de trabalho para leitores e estudiosos de Machado, o texto de apresentação, assinado por Sílvia Maria Azevedo - uma das mais experientes estudiosas da obra machadiana no país -, revela a absoluta relevância das experiências do escritor em suas atividades na imprensa, refletidas na vida cultural fluminense, de um modo geral.

Nesse ponto do livro, ficamos sabendo que, assim como a literatura produzida no Brasil, a crítica alcançou seu ponto de maior maturidade a partir da década de 1850 - sendo Machado um de seus atuantes mais representativos. Esse status, paralelo às suas atividades iniciais como tradutor e cronista, impressiona: tanto em razão da quantidade de artigos que escreveu, ao longo de mais de quatro décadas, quanto pela inegável qualidade de seus ensaios, discursos e cartas. Em suma, os textos revelam uma constante transição de fases e o acesso a múltiplas faces do autor, como observa a organizadora:

À medida que Machado de Assis, como escritor de contos e roman- 
ces, ia se voltando para práticas literárias que iriam consagrá-lo mais tarde, a começar pela publicação de Contos fluminenses, em 1870, e Ressurreição, em 1872, ambos pela editora Garnier, o crítico literário vai se sobrepondo ao crítico teatral, ao início de 1866. (p. 23)

Sob esse aspecto, o fato de Machado ter atuado em várias frentes - polígrafo que era -, provavelmente também contribuiu positivamente na versatilidade de sua escrita. Ao fazer apreciações e julgamentos de vária natureza, notamos que há uma dicção igualmente marcante, como aquela que caracteriza a sua ficção. Sílvia Azevedo repara que seu "método de análise variava e, em vez do julgamento direto, Machado fazia uso da paródia e da ironia, conforme a série de artigos publicados na Semana Ilustra$d a "$ (p.29).

Dentre os textos assinados pelo escritor, um dos mais (e justamente) renomados é "Instinto de nacionalidade", estampado no jornal O Novo Mundo - "publicação ilustrada em português, lançada em 24 de outubro de 1870, em Nova York" (p.33) -, sob encomenda do então célebre jornalista brasileiro José Carlos Rodrigues, no ano de 1873. Item constante do ensaio "Notícia da atual literatura brasileira", lá Machado afirma com coragem e precisão que "não está na vida indiana todo o patrimônio da literatura brasileira, mas apenas um legado, tão brasileiro como universal". Assim, "não se limitam os nossos escritores a essa só fonte de inspiração" (p.431).

Ao lado disso, desde muito jovem Machado tinha a consciência de que a "literatura e a política" são "duas faces bem distintas da sociedade civilizada" ( "O passado, o passado e o presente da literatura" (p.61)). Para isso, recorreu praticamente sem cessar às atividades na imprensa, mesmo porque "o espírito humano tem necessidade de discussão, porque a discussão é - movimento. Ora, o livro não se presta a essa necessidade, como o jornal" ("O jornal e o livro" (p.74)).

No papel de crítico literário, Machado de Assis combinava incisão, rigor e elegância: “O Sr. I. Azevedo é uma inteligência a formar-se; participa dos defeitos do que se chamou escola azevediana, sem todavia empregar nos seus escritos os toques superiores que o estudo mais tarde lhe há de dar" (Dário do Comércio, 2 de março de 1862 (p.99)).

Veja-se, por outro lado, como se refere a Bernardo Guimarães, autor de $A$ escrava Isaura - romance que seria publicado em 1875, dez anos após a seguinte consideração de Machado: "Com o Sr. Bernardo Guimarães dá-se um fenômeno, que não é raro em literatura: a sua popularidade não é igual ao seu talento [...] um talento tão robusto, como o do autor dos Cantos de solidão, tinha direito a mais vasta popularidade" (Diário do Rio de Janeiro, 31 de agosto de 1865 (p.228)).

Por vezes, ele revelava ainda maior empolgação com um novo autor: "Passo às letras e às artes. $\mathrm{O}$ maior acontecimento literário da quinzena foi o poema de Tomás Ribeiro, D. Jaime, cujos primeiros exemplares chegaram pelo paquete. A fama chegou com o livro, e assim, todos quantos estimam a literatura, militantes ou amadores, correram à obra mal os livreiros a puseram nos mostradores." (O Futuro, Crônica de 15 de setembro de 1862 (p.107)).

Tornou-se bastante célebre o conjunto de ressalvas que fez a Eça de Queirós, 
ocasião em que Machado havia lido $O$ primo Basílio, recém-chegado ao Brasil. Eis como o crítico brasileiro se referia ao escritor português, naquela ocasião: "O crime do padre Amaro revelou desde logo as tendências literárias do Sr. Eça de Queirós e a escola a que abertamente se filiava. O Sr. Eça de Queirós é um fiel e aspérrimo discípulo do realismo propagado pelo autor do Assomoir [Émile Zola]" (O Cruzeiro, 16 de abril de 1878 (p.467)).

As polêmicas elucubradas e fomentadas pela pena de Machado merecem especial consideração de seu leitor, mesmo porque se situam para além do que costumam enfatizar determinados manuais escolares de literatura. É sabido que um dos raros desafetos do escritor foi Sílvio Romero - que entrou para nossa história literária, por sinal, como um dos detratores implacáveis da obra machadiana.

Embora este não seja o espaço para precisar a origem das controvérsias entre um e outro, vale a pena nos determos nas palavras que o jornalista carioca dedica a $O$ santos do fim do século, livro em poesia coligido pelo pernambucano. O trecho que segue é retirado de outro ensaio machadiano bastante conhecido, dentre aqueles de maior fôlego - "A nova geração":

Pertenceu o Sr. Romero ao movimento hugoísta, iniciado no norte e propagado ao sul, há alguns anos; movimento a que este escritor atribui uma importância infinitamente superior à realidade. Entretanto, não se lhe distinguem os versos pelos característicos da escola, se escola lhe pudéssemos chamar; pertenceu a ela antes pela pessoa do que pelo estilo. (Revista Brasileira, outubro a dezembro de 1879 (p.517)

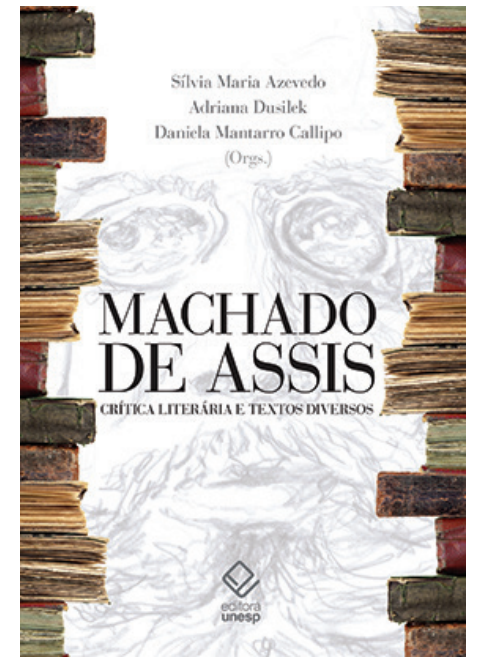

AZEVEDO, S. M.; DUSILEK, A.; CALLIPO, D. M. (Org.) Machado de Assis: critica literária e textos diversos. São Paulo:

Editora Unesp, 2013. 723p.

Como se vê, o contato com essa rica coletânea revela, em especial, o fato de que, em Machado, o crítico e o cronista irmanavam-se à beira da perfeição. É sintomático que ambas as faces do escritor tenham se interpenetrado, ao logo de sua extensa carreira. Daí não perdermos de vista um dado revelador, a esse respeito: “Os últimos textos de crítica literária de Machado de Assis coincidem com sua volta ao posto de cronista, nas páginas da Gazeta de Noticias" (p.42).

Outro fator que desperta a atenção para a decisiva colaboração de Machado reside na multiplicidade de temas sobre os quais versou, com regularidade, habitual verve e entusiasmo. Em $1^{\circ}$ de julho de 1863, lamenta n'O Futuro, o silêncio perante a morte de João Francisco Lisboa (mais conhecido, entre nós, pela alcunha de Timon): "A morte de J. F. Lisboa deve contristar por mais de um motivo. Não é só a perda de tão ilustre brasileiro que há a sentir, senão também 
o medíocre efeito que esse triste acontecimento produziu. Como se explica essa tal ou qual indiferença do Brasil vendo morrer um dos seus maiores pensadores?” (p.143).

Em seus escritos, naturalmente, há espaço de sobra para que ele defenda o papel reservado aos poetas, quase sempre em contraposição ao discurso vociferado pelos políticos de seu tempo. O texto a seguir revela uma das leituras clássicas do romancista: Demócrito, autoridade em favor de seu argumento:

Não, eu não sou dos que acham que os poetas são incapazes para a política. O que penso é que os poetas deviam evitar descer a estas coisas tão baixas, deviam pairar constantemente nas montanhas e nos cedros - como condores que são. Afinal de contas, os homens que não são sérios e graves, são exatamente os homens graves e sérios. Demócrito continua a ter razão: só é sério aquilo que o não parece. (Diário do Rio de Janeiro, Crônica de 22 de novembro de 1864 (p.203))

Para o leitor acostumado à saborosa ficção machadiana - disposta em seus nove romances, duas novelas, mais de duas centenas de contos, além das crônicas, poesias, peças teatrais e traduções -, a presente obra cumpre outro relevante papel: o de resgatar as numerosas e agudas contribuições do escritor, como crítico literário. Em suas leituras, o autor foi um dos primeiros a reconhecer em José de Alencar o ocupante do "primeiro lugar na literatura brasileira" ("Prefácio" a O Guarani, 1887 (p.567)).

O contato com tão variados textos, enfeixados em um único volume, além de constituir oportuno material de estudo, mostra como a dicção machadiana comparece em suas demais atividades com a pena - tendo sido ele um autêntico juiz de nossa cultura, particularmente no que se refere ao universo das letras. Esse saudável contágio entre diferentes artes no reino da palavra, exercidas com reconhecido esmero, explica o alto grau de coesão que perpassa a sua obra, marcada por rigorosa e constante autocrítica.

Como afirmou o próprio Machado de Assis, no conhecido artigo "Ideal do crítico": "para a representação literária, como para a representação política, é preciso ter alguma coisa mais que um simples desejo de falar à multidão. Infelizmente é a opinião contrária que domina, e a crítica, desamparada pelos esclarecidos, é exercida pelos incompetentes" (Diário do Rio de Janeiro, 8 de outubro de 1865 (p.236)).

Fiquemos com o alerta machadiano. Dito isso, voltemos a atenção para o meticuloso trabalho organizado por Sílvia Maria Azevedo, Adriana Dusilek e Daniela Mantarro Callipo. Além de saborear as múltiplas vozes do escritor, em suas atividades para além da esfera literária no período de mais de quarenta anos, festejemos a publicação de uma obra que favorecerá novos estudos sobre Machado, com a vantagem de contarmos com a reunião de farto material, e de excelente qualidade, em um só lugar.

Jean Pierre Chauvin é coordenador do Curso de Letras da Faculdade de Diadema (Grupo Uniesp) e professor da Fatec São Caetano do Sul. Pesquisador de pós-doutorado do Departamento de Letras Clássicas e Vernáculas, na USP.

@ - tupiano@usp.br

${ }^{\text {I }}$ Faculdade de Filosofia, Letras e Ciências Humanas, Universidade de São Paulo, São Paulo/SP, Brasil. 